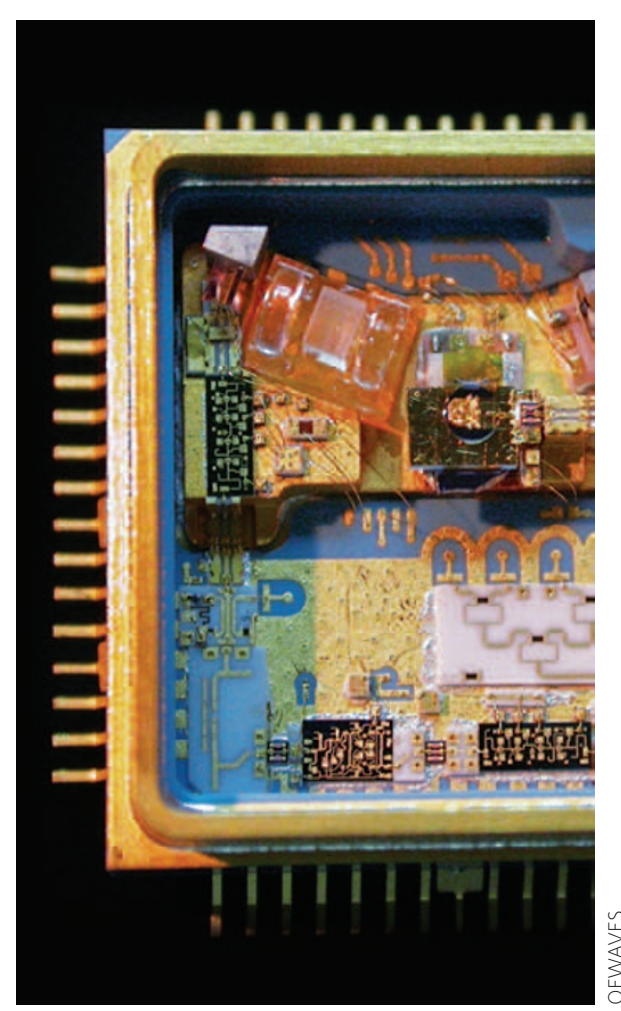

COVER IMAGE

Close-up of the optoelectronic oscillator technology developed by US firm OEwaves.

NPG ASIA-PACIFIC

Chiyoda Building 2-37

Ichigayatamachi, Shinjuku-ku, Tokyo

162-0843 Japan

$\mathrm{T}:+81332678751$

F: +81332678746

naturephoton@nature.com

EDITOR

OLIVER GRAYDON

PRODUCTION EDITOR

CHRIS GILLOCH

COPY EDITOR

JAMES BAXTER

ART EDITOR

TOM WILSON

SALES ACCOUNT MANAGER

KEN MIKAMI

$\mathrm{T}:+81332678751$

ADVERTISING DIRECTOR

GEORGE LUI

$\mathrm{T}:+14157813804$

ADVERTISING MANAGER

SIMON ALLARDICE

$\mathrm{T}:+14154039034$

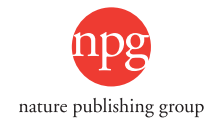

\title{
Long live radio
}

$\mathrm{T}$ he fortuitous combination of maturing capabilities, falling component prices and rising demand bodes well for the future of microwave photonics and radio-overfibre technologies, according to opinions gathered in this month's Technology Focus on the topic (see page 724).

Initially inspired and driven by the military for battlefield applications such as radar and high-speed secure communications, radio-over-fibre technology is now increasing being used to provide high-speed wireless data services in civilian structures such as shopping malls, hospitals, stadiums, power plants and other large buildings. Zinwave, a start-up currently commercializing radio-over-fibre technology developed at universities in the $\mathrm{UK}$, is building a growing business on this opportunity (see page 726 ).

Although the future of telecommunications is often described as being a completely digital world, it should not be forgotten that optical fibre is also an attractive and capable conduit for transporting highfrequency analog signals. Indeed, the use of optical fibre rather than coaxial cable - the traditional means of carrying radiofrequency signals - has some compelling benefits. For a start, the attenuation of optical fibre is typically only $0.1 \mathrm{~dB} \mathrm{~km}^{-1}$, which is around 3,000 times lower than coaxial cable. Second, optical fibre is considerably less bulky and far lighter in weight than coaxial cable, which simplifies the installation process.

The attraction of this technology doesn't end with the optical fibre. Optoelectronic and photonic devices such as lasers, microring and whispering gallery mode resonators and interferometers can be used to generate and process high-frequency radiofrequency signals that cannot easily be produced directly in the electronic domain (see pages 728 and 731). Many researchers are now striving to create integrated optical circuitry that can perform such tasks on the chip-scale, thus simplifying the massproduction and packaging stages.

One thing is for certain: despite the popularity of digital data formats, radio transmission is alive and kicking.

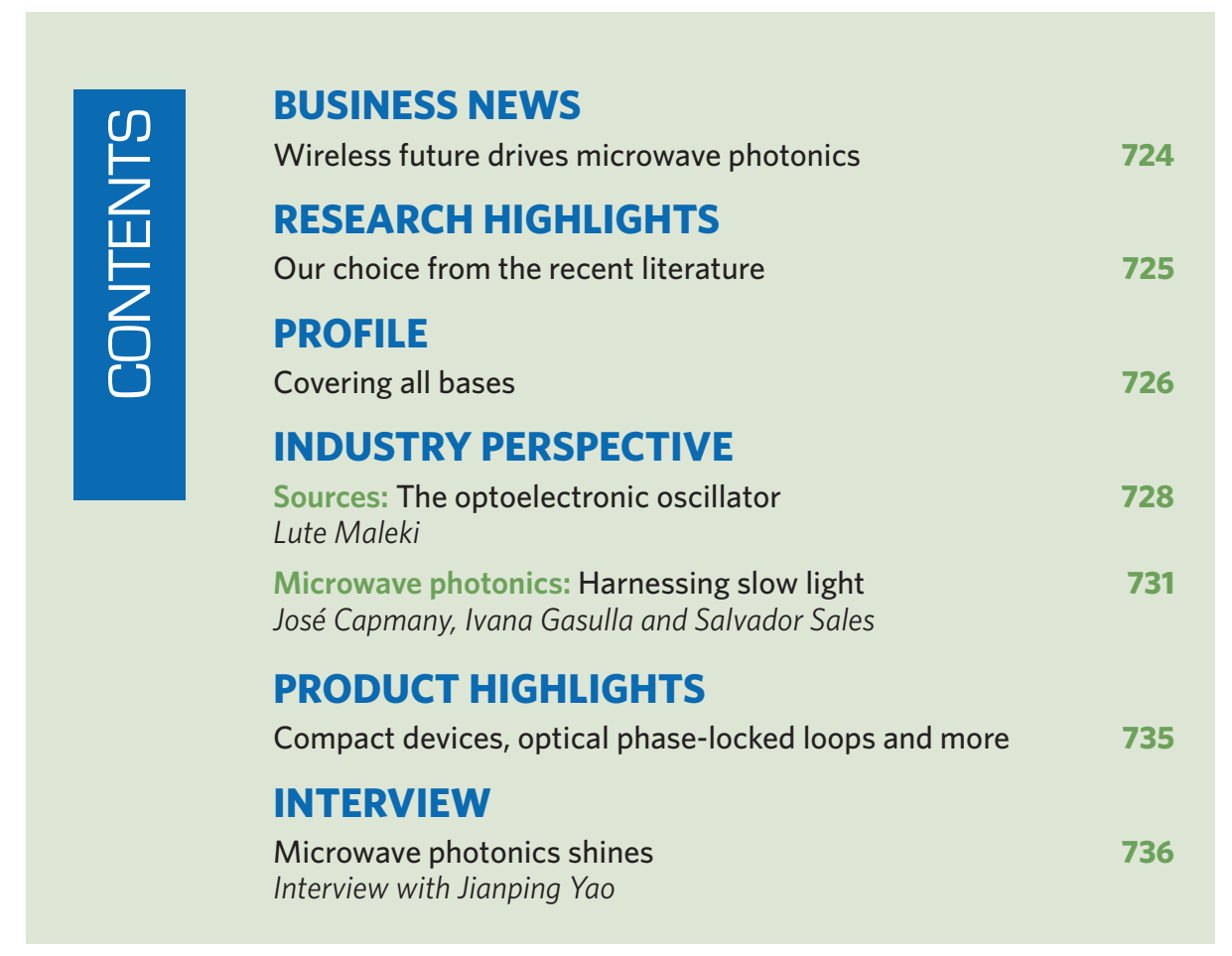

